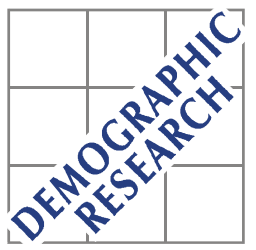

Demographic Research a free, expedited, online journal of peer-reviewed research and commentary in the population sciences published by the Max Planck Institute for Demographic Research Doberaner Strasse 114 D D-18057 Rostock · GERMANY www.demographic-research.org

DEMOGRAPHIC RESEARCH

VOLUME 5, ARTICLE 3, PAGES 65-78

PUBLISHED 05 OCTOBER 2001

UPDATED 04 DECEMBER 2001

www.demographic-research.org/Volumes/Vol5/3/

DOI: $10.4054 /$ DemRes.2001.5.3

Demographic trends in Sweden:

Childbearing developments in 1961-1999, marriage and divorce developments in

1971-1999

\title{
Gunnar Andersson
}

\section{Liu Guiping}

(C) 2001 Max-Planck-Gesellschaft. 


\section{Table of Contents}

$\begin{array}{ll}\text { Summary } & \text { A } 2\end{array}$

Fluctuating fertility in Sweden... $\quad$ A 2

... and yet another turning point in $1997 \quad$ A 2

Long-term decline in the propensity to get married A 3

- but an unexpected trend reversal in 1999

A 3

$\begin{array}{ll}\text { Concerning our investigation } & \text { A } 3\end{array}$

References $\quad$ A 5

$\begin{array}{ll}\text { Figures } & \text { A } 6\end{array}$ 


\title{
Demographic trends in Sweden: Childbearing developments in 1961-2000, marriage and divorce developments in 1971-1999.
}

\author{
Gunnar Andersson ${ }^{1}$ \\ Liu Guiping ${ }^{2}$
}

\begin{abstract}
In the present note, we display the main features of recent trends in family-demographic behavior in Sweden. We update previously published indexes of marriage, divorce, and childbearing risks by calendar year in order to cover the developments up to 1999 (marriage and divorce) and 2000 (childbearing), adding another two and three years of observation to our series.
\end{abstract}

1 Max Planck Institute for Demographic Research, Doberaner Straße 114, D-18057 Rostock, Germany. Email: andersson@demogr.mpg.de

2 Max Planck Institute for Demographic Research, Doberaner Straße 114, D-18057 Rostock, Germany. Email: liu@ demogr.mpg.de 


\section{Summary}

The latest decline in Swedish birth rates, initiated at the beginning of the 1990s, eventually came to a halt at the end of the same decade. For mothers at all parities and for childless women in their 30s, trends were reversed into clear increases in birth propensities in 1998-2000. In 2000, trends were also reversed for childless women at the younger ages. Marriage propensities as well show a trend reversal in the last year of the $20^{\text {th }}$ century in that they increased for women at all parities and non-married civilstatus categories. The long-term trend of increasing divorce risks continued uninterruptedly in 1998 and 1999.

\section{Fluctuating fertility in Sweden...}

Childbearing trends in Sweden have been highly volatile throughout the four last decades of the $20^{\text {th }}$ century. First-birth fertility of younger women (16-28 years) decreased continuously from the mid-1960s to the mid-1980s. This decline was followed by a marked increase in first-birth fertility of older women, together reflecting a general postponement of the entry into motherhood in Sweden (Figure 1). During the baby boom period of the 1980s, birth propensities also increased strongly for mothers at different parities (Figures 2-3) - as well as for the younger childless. By contrast, the 1990s instead display strong declines in birth risks. As in the 1980s, these trends were followed by practically all demographic sub-groups of women. The declines were strongest in first-birth risks of younger women and in third- and fourth-birth risks while the decline in first-birth risks of older women was rather unimportant.

\section{... and yet another turning point in 1997}

After signs in 1997 of a decreasing pace of the decline in birth risks, we eventually note a clear trend reversal in birth propensities in 1998-2000. For the first time in several years, birth risks of mothers (Figures 2-3) and of childless women in their 30s and 40s (Figure 1) then increased again. For younger childless women (Figure 1), the decrease just slowed down a bit in 1999 but in 2000 , we note a trend reversal also for this group of women. It is interesting to note that the trend reversal in 1998-1999 not is evident if one only has access to aggregated data like those of Total Fertility Rates. The TFR of Sweden was recorded to 1.50 in these two years, the lowest level ever registered for that country. With our presentation, we can get a picture of the underlying behavior of 
different subgroups of Swedish women, revealing that important changes have occurred recently in the childbearing dynamics.

\section{Long-term decline in the propensity to get married - but an unexpected trend reversal in 1999}

During the 1970s, the propensity for Swedish women to marry decreased dramatically and it has continued to decline ever since, though at a much more moderate pace (Figure 4). In sharp contrast to this long-term trend, we find a spectacular but temporary increase in marriage-formation risks in 1989 in response to the introduction of new rules concerning the eligibility for a future widow's pension. Interestingly, we find another trend reversal exactly ten years after 1989 but this time at a much smaller scale. Marriage propensities increased slightly in 1999 for never-married women at all parities (Figure 5) as well as for first-divorced women with different categories of children (Figure 6). We have no idea if it this time merely was the turn of the century that stimulated more people to arrange for a marriage or if this latest trend reversal reflects some other underlying change in behavior.

\section{Continued increase in Swedish divorce risks}

The divorce risk increased sharply in 1974 in response to liberalizing changes that became effective in the divorce legislation that year. From the end of the 1980s, divorce risks have increased again but this time on a more regular basis (Figure 7). The increase in 1974 was mainly due to an increased propensity for divorce among childless women, while the increases from the late 1980s onwards instead were due to increasing divorce risks of mothers (Figure 8), who constitute the vast majority of married women. The trend of increasing divorce risks went on also during the last two years of the last decade.

\section{Concerning our investigation}

In the present note, we have provided an update of previous presentations of trends in family-demographic behavior of women in Sweden so that we now can cover the nuptiality developments up to 1999 and the childbearing developments up to 2000 . Trends are given in the manner of time series of indexes of the propensity of a woman 
to form a marriage, to divorce, or to give birth in a specific calendar year. The indexes are given relative to a suitable baseline year in the same manner as a price index reflects prices relative to a selected year. A divorce index of 1.20, for example, means that the risk of divorce was 20 percent higher in that year than in the baseline year we use. In our calculations, we standardize for the effect of a number of demographic background variables, which means that we control for the effect of compositional changes among women over the categories of these variables. We focus explicitly on the effect of the number of children on the demographic behavior in that we present separate indexes for women at different parities.

Our calculations are based on data derived from the Swedish population registers made available to us by Statistics Sweden. We have had access to information on the dates of all births and civil-status changes in Sweden of practically all women born in that country. We base our childbearing analyses on all women born in Sweden in 1925 onwards while our study on civil-status changes are based on women born after 1945 . The registration of divorces was not fully reliable before 1968 so we choose to restrict our study on civil-status changes to the period from 1971 and onwards. We present trends in childbearing in 1961-2000. The present update of previous presentations adds another two or three years of observation to our picture. For an earlier study, which also contains a thorough description of our system of period analysis, see Andersson (1999b). For further information on specific aspects of the divorce dynamics in Sweden, see Andersson (1997). For corresponding information on marriage-formation patterns, see Andersson (1998), while we refer to Andersson (1999a) for the same type of information on the childbearing dynamics in Sweden. 


\section{References}

Andersson, G., 1997. The impact of children on divorce risks of Swedish women. European Journal of Population 13: 109-145.

Andersson, G., 1998. Trends in marriage formation in Sweden 1971-1993. European Journal of Population 14: 157-178.

Andersson, G., 1999a. Childbearing trends in Sweden 1961-1997. European Journal of Population 15: 1-24.

Andersson, G., 1999b. Trends in childbearing and nuptiality in Sweden, 1961(71)-1997. Stockholm Research Reports in Demography, No. 133. Stockholm University Demography Unit. Also in: Andersson, G., Trends in Childbearing and Nuptiality in Sweden: A Period Analysis. Stockholm University Demography Unit - Dissertation Series. 
Figure 1: Annual index of first-birth rates. Swedish childless women, 1961-2000, by group of ages, standardized for exact age.

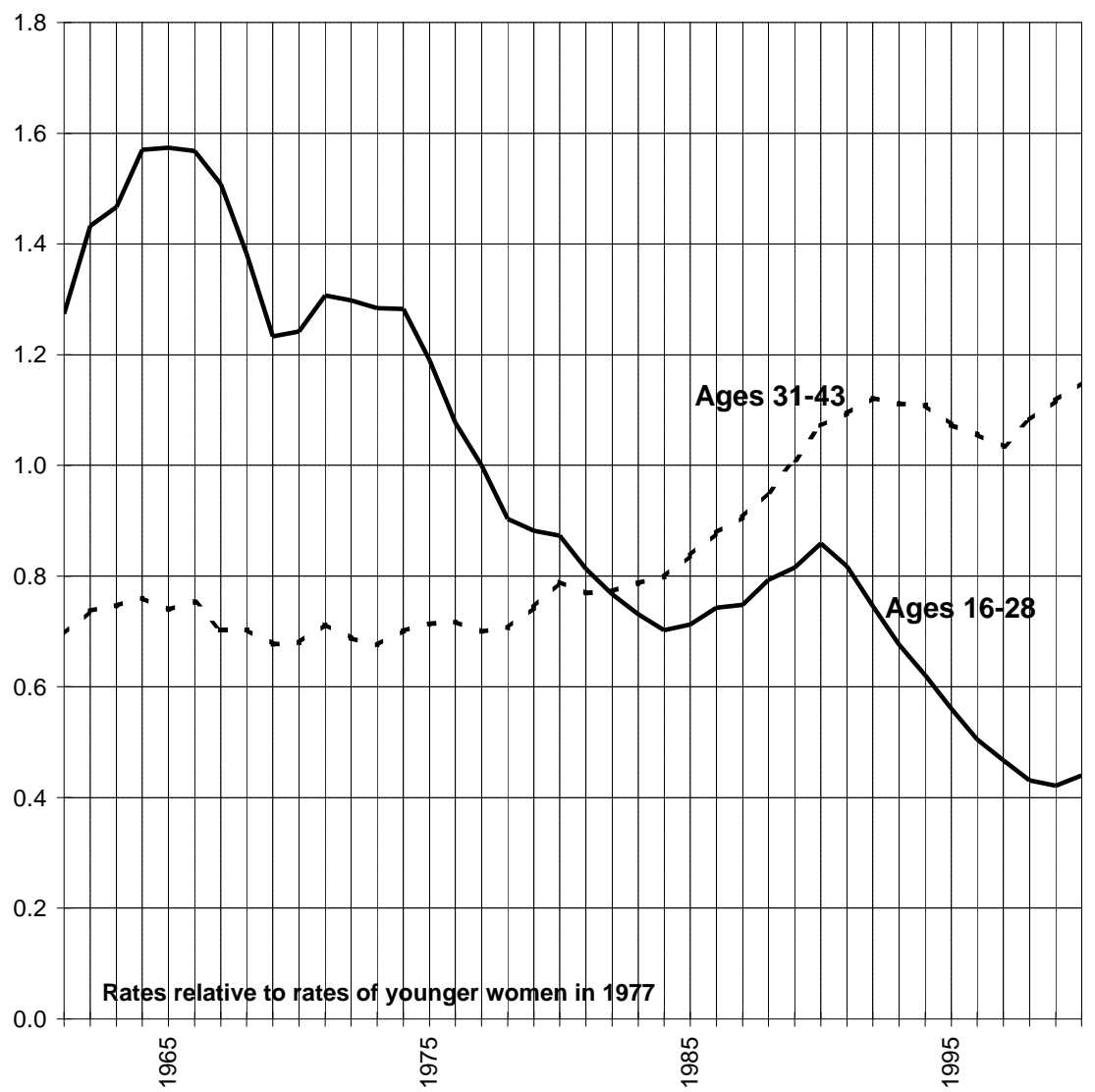


Figure 2: Annual index of second-, third-, and fourth-birth rates. Swedish mothers, 1961-2000, by birth order, standardized for age of mother and age of her youngest child.

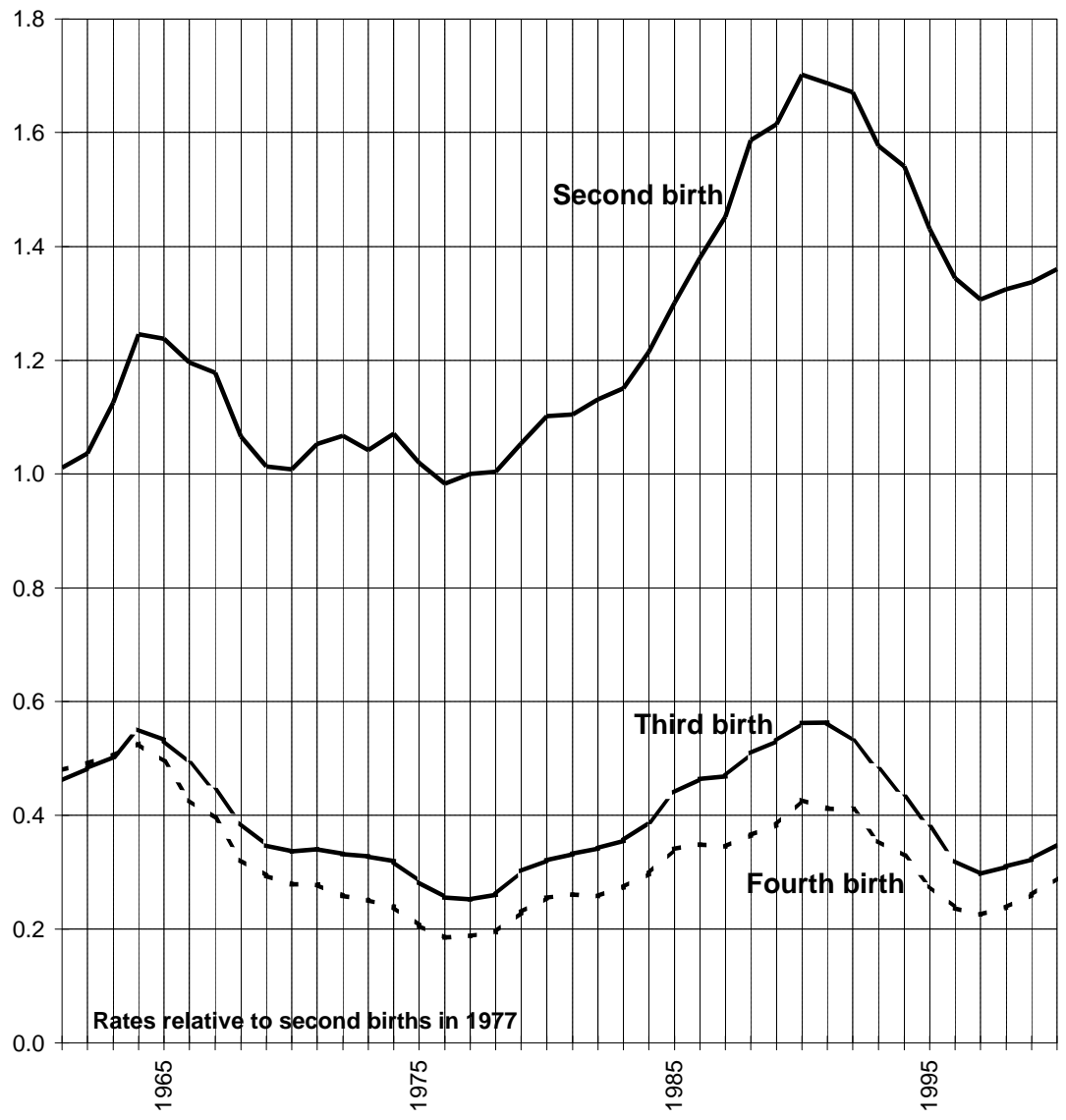


Figure 3: Annual index of second-, third-, and fourth-birth rates. Swedish mothers, 1961-2000, by birth order, standardized for age of mother and age of her youngest child.

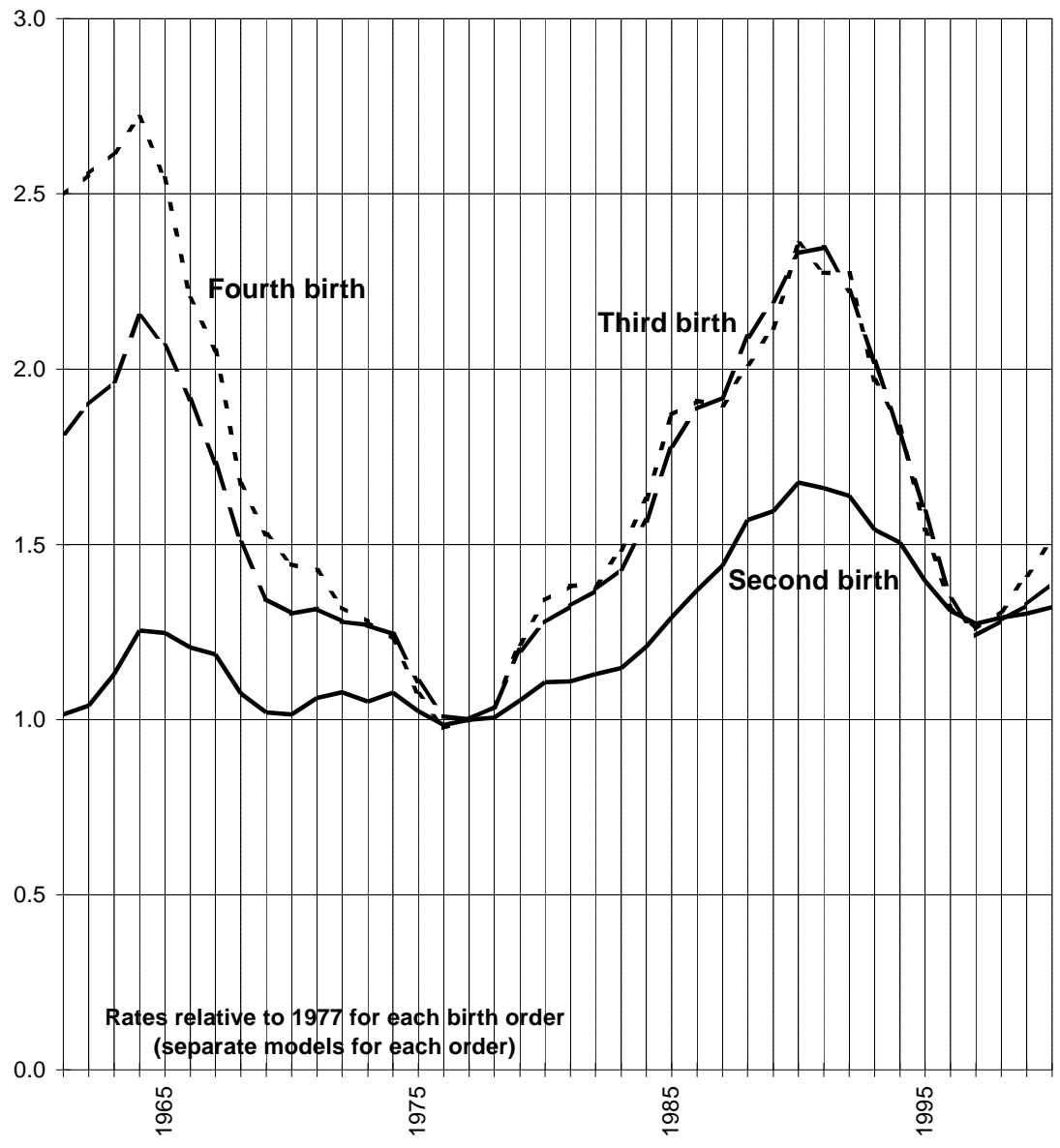


Figure 4: Annual index of marriage-risk level. Never-married Swedish women, 1971-1999, standardized for parity and age.

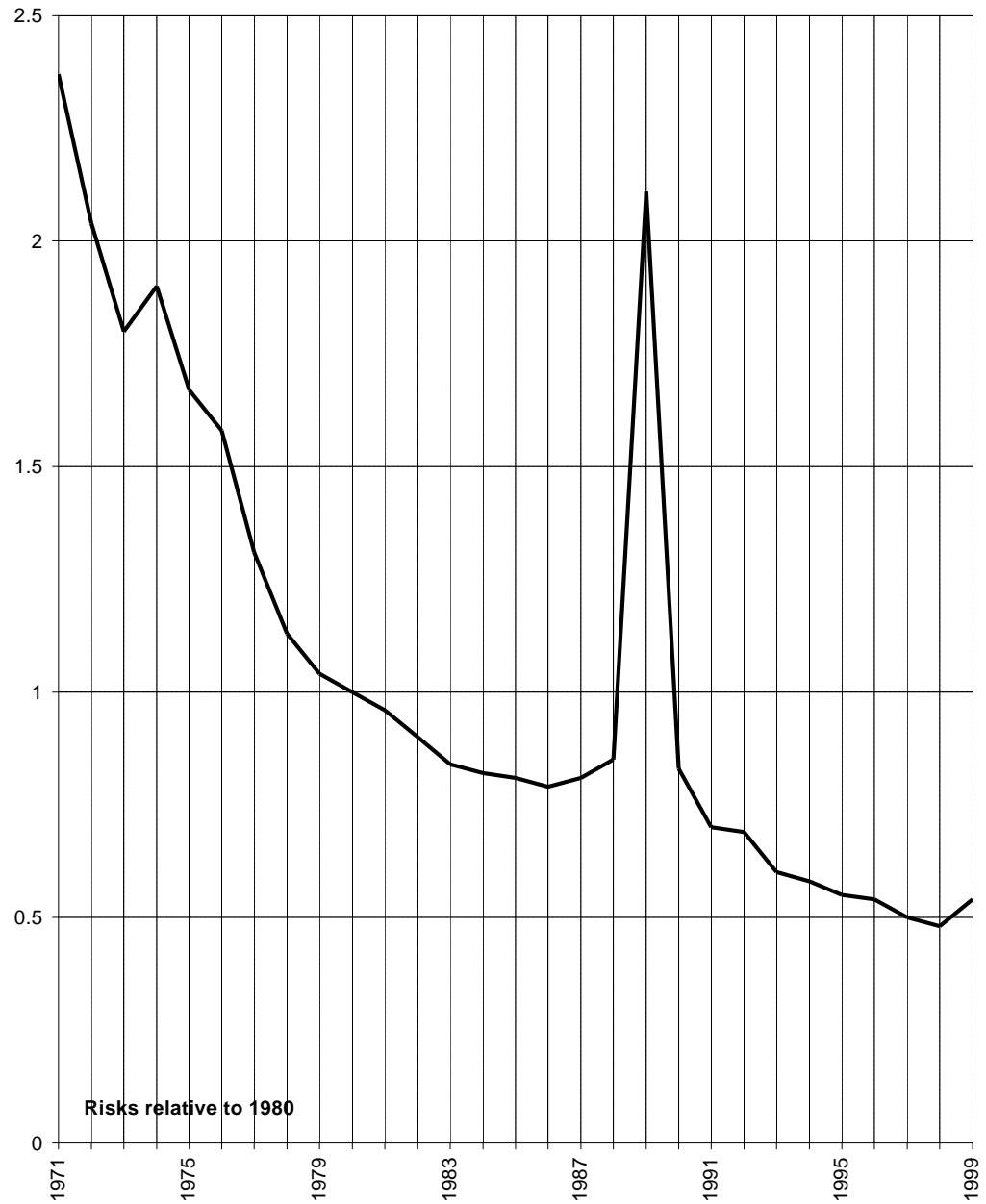


Figure 5: Annual index of marriage-risk level. Never-married Swedish women, 1971-1999, by parity, standardized for age.

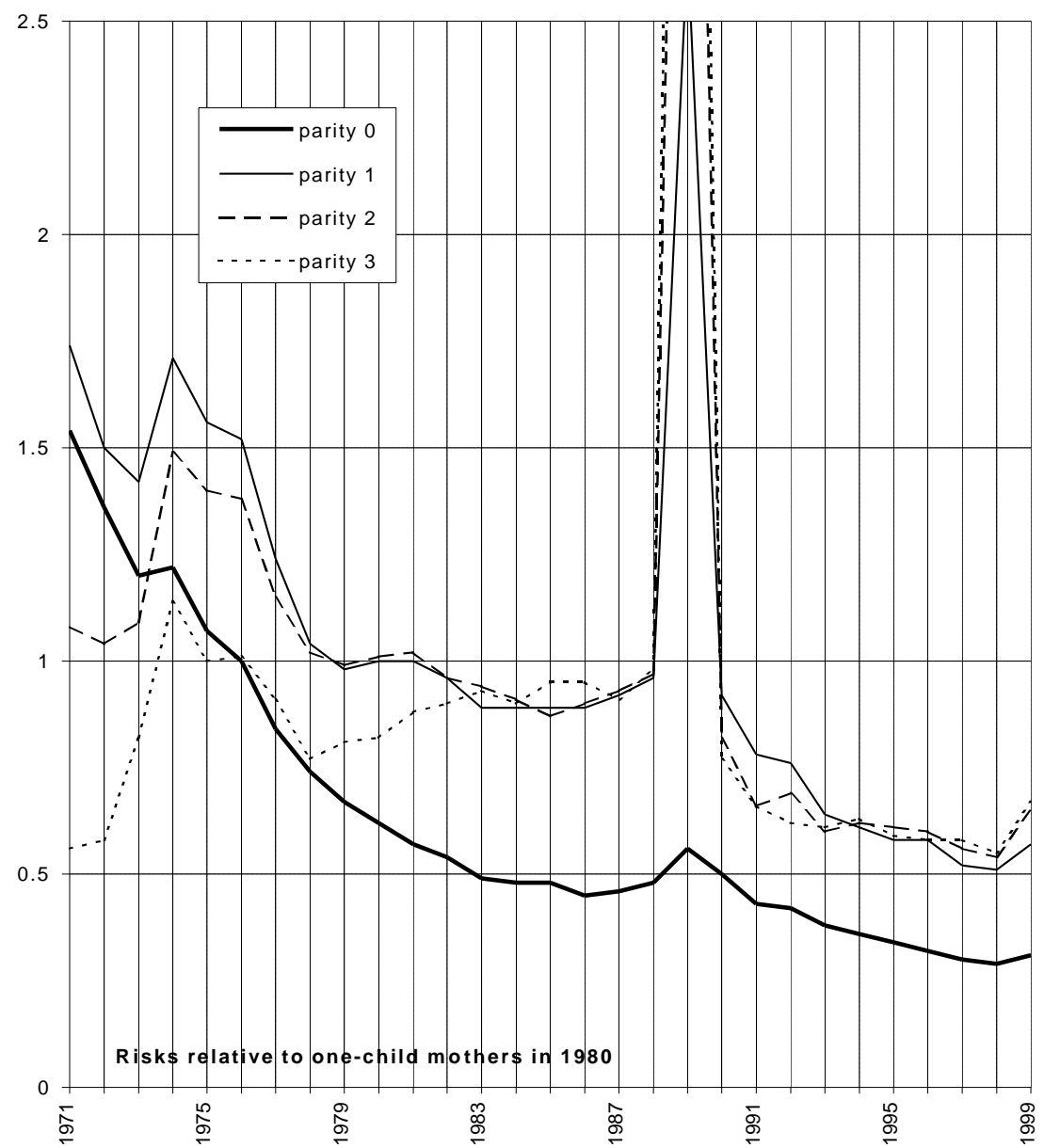


Figure 6: Annual index of remarriage-risk level. First-divorced Swedish women, 1971-1999, by parity, standardized for age and time since divorce.

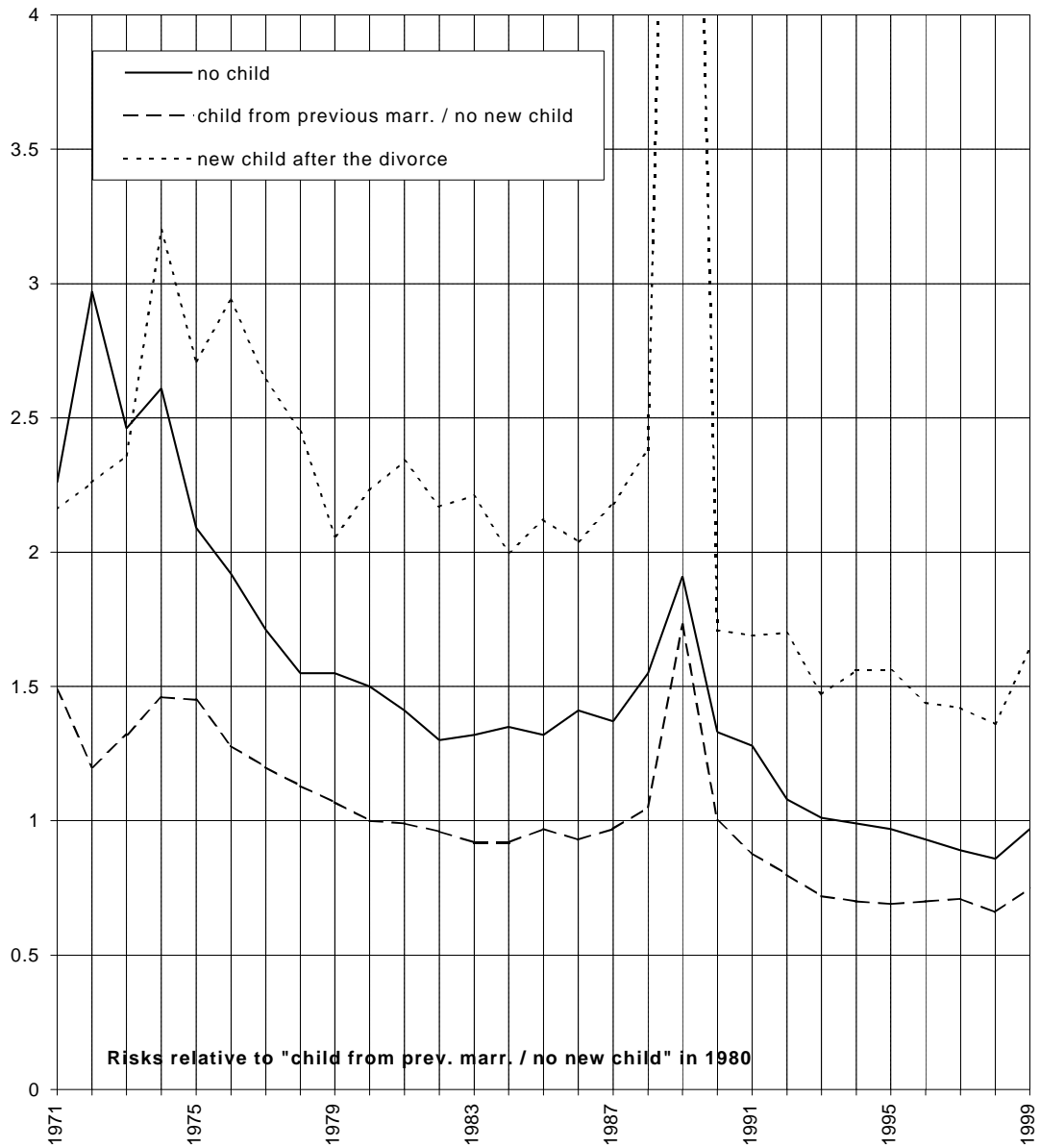


Figure 7: $\quad$ Annual index of divorce-risk level. First-married Swedish women, 19711999, standardized for age at marriage, parity, age of youngest child, premarital birth, and duration.

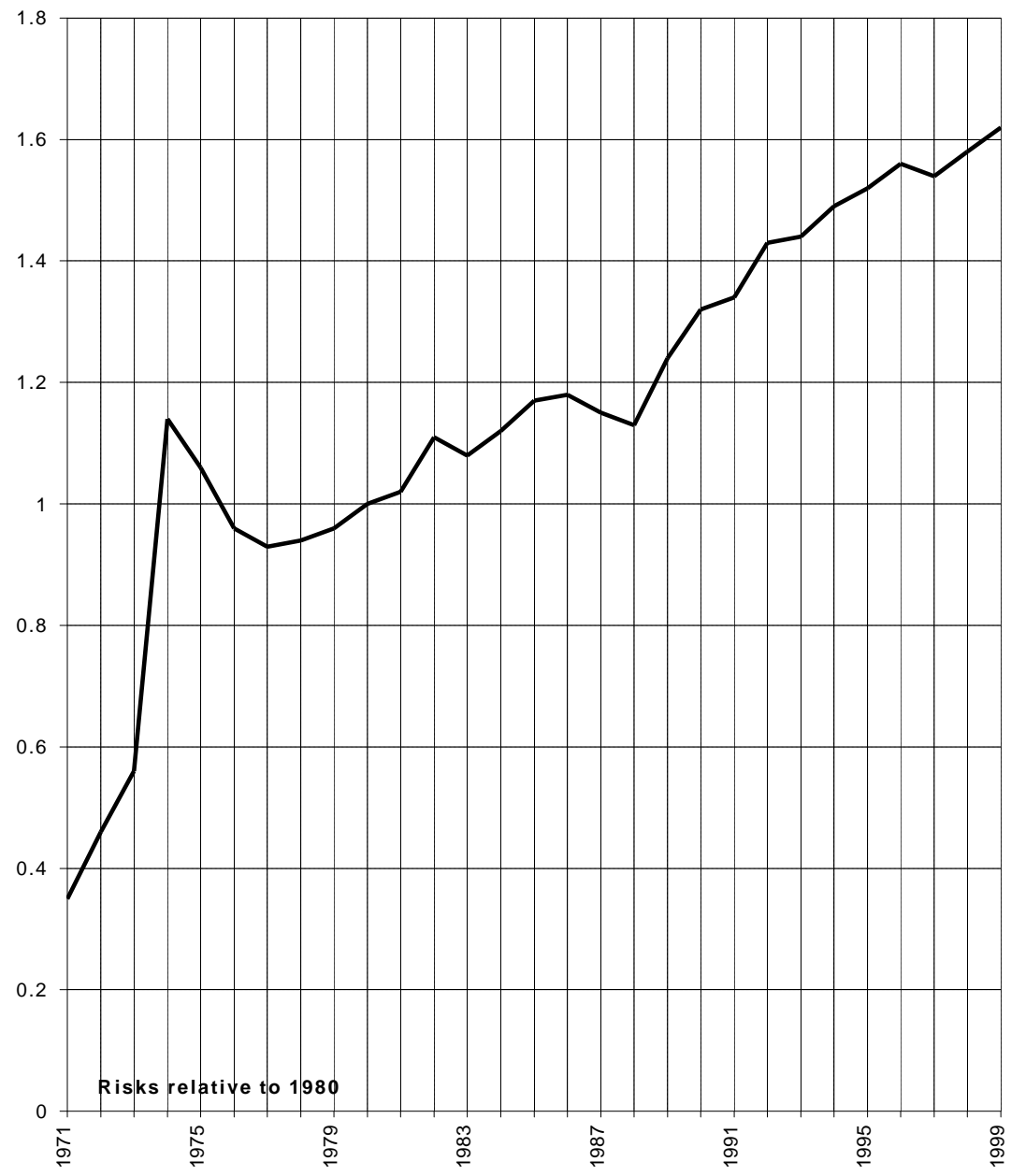


Figure 8: $\quad$ Annual index of divorce-risk level. First-married Swedish women, 19711999, by parity, standardized for age at and duration of marriage. Risks for mothers also standardized for presence of premarital children and age of youngest child.

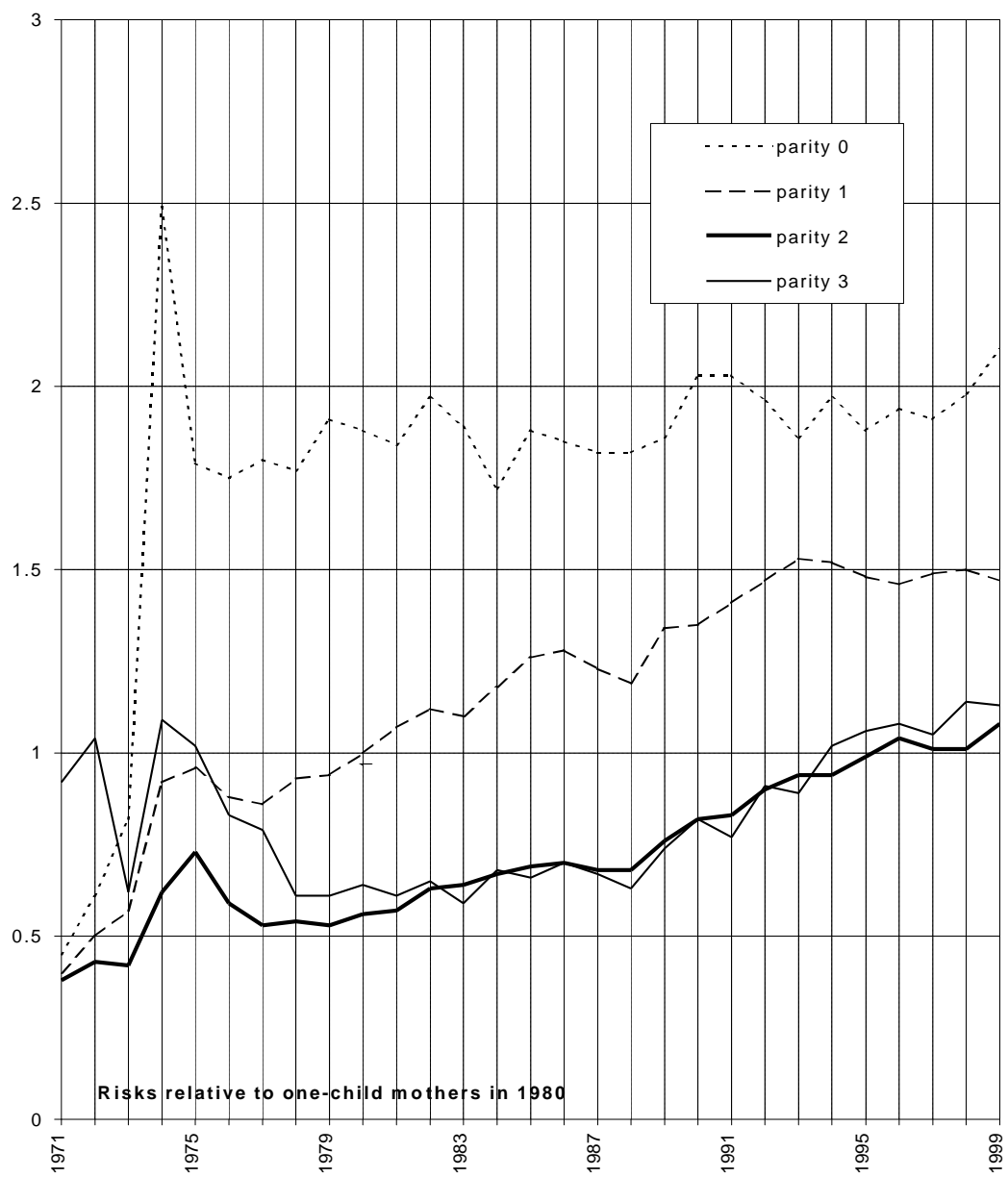


Demographic Research - Volume 5, Article 3 updated 